\title{
Heart Rate Variability and Cardiovascular Fitness: What We Know so Far
}

\author{
Hugo Celso Dutra Souza (D) \\ Stella Vieira Philbois (D) \\ Ana Catarine Veiga (D) \\ Bruno Augusto Aguilar (D)
}

Department of Health Science, Ribeirão Preto Medical School of University of São Paulo, São Paulo, Brazil
Correspondence: Hugo Celso Dutra Souza

Ribeirão Preto Medical School, University of São Paulo, Laboratory of Exercise Physiology and Cardiovascular Physiotherapy, Av. Bandeirantes, 3900 -

Vila Monte Alegre - Ribeirão Preto, São

Paulo, 14049-900, Brazil

Tel +55I633 I5-44I6

Fax +55I633I5-44I3

Email hugocds@fmrp.usp.br
Abstract: Fluctuation analysis in intervals between heartbeats provides important indices related to autonomic modulation of heart rate variability (HRV). These indices are considered predictors of morbidity and mortality as they are frequently altered in patients with chronic degenerative diseases, especially in those with cardiovascular and metabolic diseases. Similarly, a reduction in HRV is common with aging. In all cases, cardiovascular fitness is often reduced to below the predicted values. In turn, increases in cardiovascular fitness through regular physical exercise, especially aerobic exercise, represent an important therapeutic tool capable of promoting positive adjustments in cardiac autonomic modulation. These adjustments are characterized by reduced sympathetic modulatory influence and/or increased vagal modulatory influence on the heart, increasing the HRV. Therefore, several methodological tools have been used to assess the degree of impairment of autonomic modulation and the therapeutic effects of physical exercise. In contrast, establishment of strict protocols in experimental design is a main challenge in establishing HRV analysis as a robust parameter for evaluating cardiovascular homeostasis. Thus, this review aimed to contribute to the understanding of autonomic modulation of HRV and its relationship with cardiovascular fitness, highlighting the advances made thus far, the applicability of analysis tools, and the confounding factors observed frequently.

Keywords: heart rate variability, cardiovascular fitness

\section{Introduction}

In the lasted decades, there has been an exponential increase in interest in the investigation of variability in autonomic modulation of cardiovascular parameters, such as heart rate variability (HRV) and blood pressure variability (BPV), ${ }^{1-4}$ as this form of analysis enables noninvasive assessment and evaluation of selective cardiovascular autonomic function. In this case, studies have shown that impairment in cardiac autonomic modulation is directly related to adverse cardiovascular events. ${ }^{5-8}$

These observations were only possible with the advancement of new computational technologies that allowed the development and creation of easy-to-apply methodological tools. Initial studies were related to the study of HRV modulation, performed using tools based on linear analysis of the time interval oscillations between consecutive heartbeats, providing referential indices of cardiac modulatory parameters attributed to the autonomic nervous system. ${ }^{4,6}$ These autonomic parameters of HRV were initially standardized by the European and American Cardiology Societies and later resulted in the publication of a Task Force (1996), which is still used today as a worldwide reference and basis for the literature on the application and interpretation of tools used. 
From a historical point of view, the first studies that effectively investigated HRV parameters were conducted in the 1960s, when HRV analysis was used to monitor fetal distress. ${ }^{9}$ From the 1970s, new studies correlated HRV parameters with pathophysiological situations, such as the increased risk of mortality, in patients with cardiovascular diseases and/or diabetes associated with autonomic neuropathy. ${ }^{10,11}$ However, the clinical importance of HRV analysis studies has only been consolidated since the 1980s, with the advent of computer techniques associated with the processing of biological signals, when it was shown that reduction in HRV was significantly correlated independently with the prediction of mortality after acute myocardial infarction (AMI). ${ }^{12,13}$ Furthermore, the predictive values of HRV autonomic parameters, when investigated in association with other parameters frequently used in medical practice such as echocardiography and electrocardiography, such as reduced ejection fraction, ventricular ectopic activity, and the presence of late potentials, appear to increase the clinical value of prediction of numerous cardiac pathologies. ${ }^{7,8}$

\section{Analysis Methodologies Linear Method}

Several linear methods have been developed for the quantification of HRV oscillations. Among them, stand out the analyses in the time and frequency domains. In the time domain, the most common methods used involve statistical and geometric indices, whereas in the frequency domain, the most common method used is spectral analysis. The latter allows the quantification and differentiation of oscillations on the abscissa axis $(\mathrm{Hz})$ according to their frequency of occurrence and assessment of the power of oscillations on the ordinate axis. ${ }^{4}$ In studies investigating long-term heart rate (HR) oscillations (24 h), time domain analysis is generally used. However, in studies investigating short-term HR oscillations (eg, $10 \mathrm{~min}$ ), frequency domain analysis is preferably used. ${ }^{4}$ Although, new techniques are emerging that address this and enable frequency domain measurement. ${ }^{14}$

\section{Nonlinear Method}

Nonlinear analyses involving mathematical calculations considering the regulation dynamics of the system in an unpredictable way are also widely studied. Among the nonlinear analyses, Poincare plot analysis, symbolic analysis, entropy, and fractal methods stand out. ${ }^{4,15,16}$

\section{Heart Rate Variability and Diseases Cardiovascular Diseases}

In general, cardiovascular diseases are accompanied by impairments in cardiac autonomic control, characterized by reduced baroreflex sensitivity (BRS), increased sympathetic tone, and/or reduced cardiac parasympathetic (vagal) tone ${ }^{17}$ Most studies have also indicated significant imbalances in the autonomic modulation of HRV. The cause of these imbalances in cardiac autonomic regulation is generally associated, supporting the role of sympathetic nerve activity (SNA) in disease progression. ${ }^{18,19}$ In this case, it is common to observe acute changes in cardiac autonomic control, such as acute myocardial infarction, which is characterized by significantly high sympathetic autonomic drive associated with a reduction in vagal drive, and chronic elevations of the sympathetic drive, as seen in heart failure. This is the final route of most cardiac disease and events, such as myocardial infarction, coronary artery disease, cardiomyopathy, and systemic arterial hypertension. The reason for these adjustments, which can be characterized as adverse because they promote inadequate cardiac adaptations, is based on the pressing need to meet the individual's basal metabolic demand, ie, to maintain a satisfactory cardiac output for all body tissues. However, the chronic character of cardiovascular disease continuously hyperactivates the sympathetic autonomic component, causing long-term impairments. ${ }^{20-23}$ Concomitantly, the literature reveals an increase in stimulation of the renin-angiotensin-aldosterone system, which causes an increase in the concentration angiotensin II and release of reactive oxygen species, favoring oxidative stress and endothelial dysfunction and providing positive feedback on increased SNA. ${ }^{19,21,24,25}$ This reorganization corroborates the global reduction in HRV (Figure 1). In this case, HRV indices are important markers of an increased risk of cardiac events and sudden death in these individuals. $^{7,21,26-28}$

\section{Metabolic Diseases}

In addition to cardiovascular diseases, metabolic diseases such as obesity, metabolic syndrome, and type I and II diabetes mellitus, have similar autonomic characteristics and are associated with a prominent reduction in HRV in addition to impairments in lipid and glucose metabolism, reduction in insulin sensitivity, increased levels of inflammatory markers. ${ }^{29-32}$ The reduction in HRV has been extensively discussed; however, patients with a high 


\section{NORMOTENSIVE MEN}

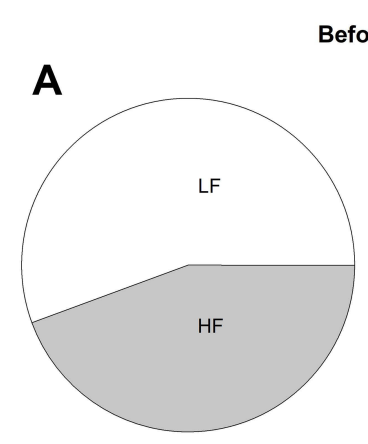

Before training

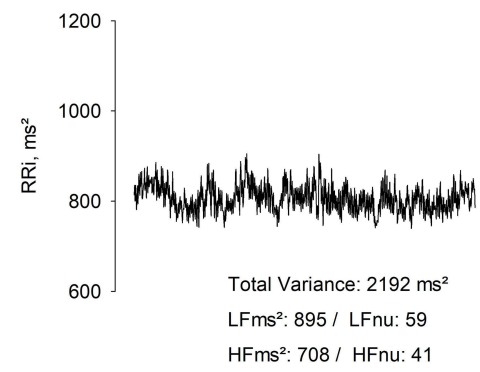

\section{HYPERTENSIVE MEN}

Before training

B

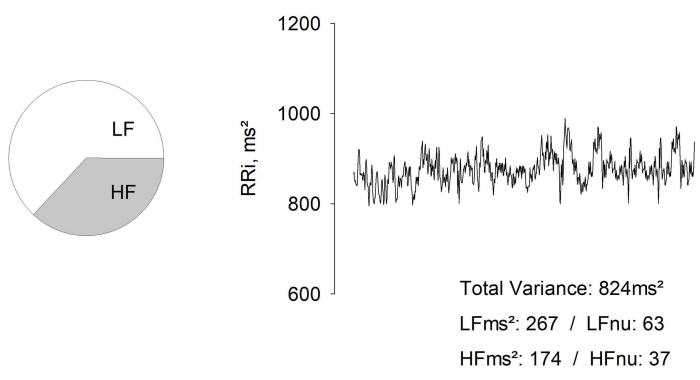

After training

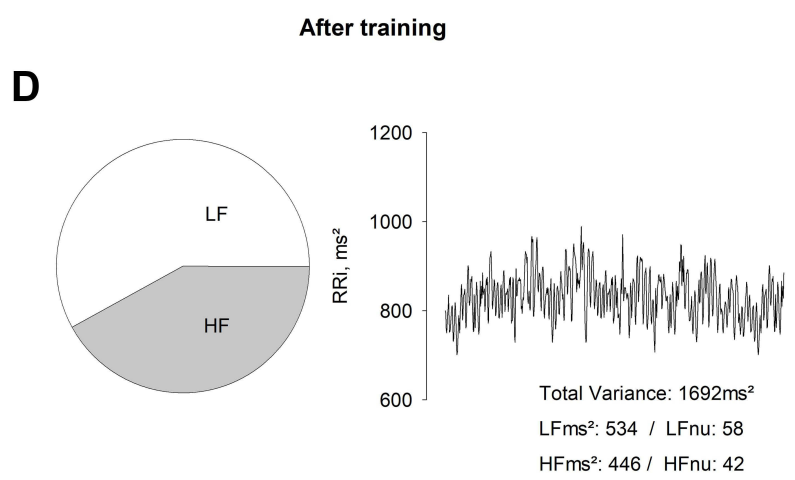

Total Variance: $2241 \mathrm{~ms}^{2}$

LFms²: 820 / LFnu: 53

HFms': 761 / HFnu: 47

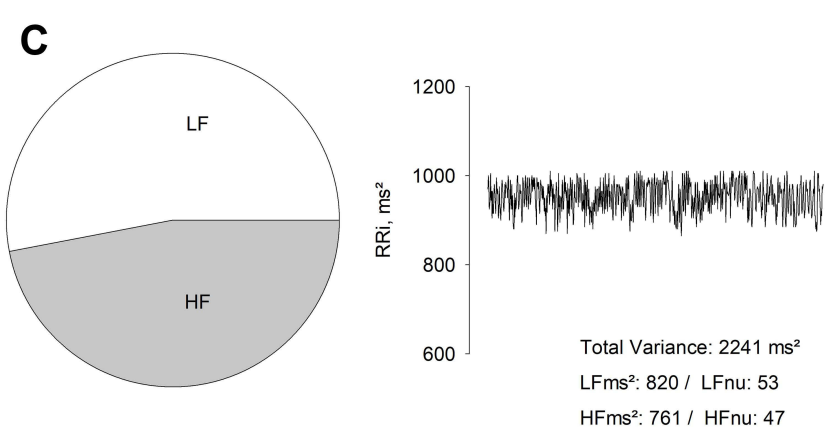

Figure I Representative illustration of heart rate variability parameters through spectral analysis in normotensive (A and $\mathbf{C})$ and hypertensive (B and $\mathbf{D})$ men obtained in our laboratory, before and after 16 weeks of aerobic physical training. The RR intervals (RRi) in absolute units (ms $\left.{ }^{2}\right)$ time series are illustrated by the line chart and was used the low-frequency (LF) and high-frequency (HF) bands in normalized units (nu) to indicated the relationship between autonomic modulation balance by the pie chart.

percentage of body fat, increased waist circumference, accumulation of visceral fat, and increased body mass index have decreased vagal modulation and increased sympathetic modulation. ${ }^{33,34}$ Furthermore, changes in glucose and insulin metabolism lead to changes in autonomic control, characterized by increased sympathetic modulation and/or reduced vagal modulation. According to some studies, insulin stimulates the sympathetic autonomic component, ${ }^{35}$ and increases leptin concentration. ${ }^{32,36}$ In addition, it has been shown that leptin would influence the solitary tract nucleus (NTS) in experimental animals, decreasing the BRS. ${ }^{37}$ In turn, in metabolic diseases, an increase in pro-inflammatory cytokines, such as interleukin-6 and tumor necrosis factor (TNF)- $\alpha$, is frequently observed. These cytokines may be responsible, at least in part, for the impairment in endothelial vasodilator function and a reduction in $\mathrm{HRV}^{38-40}$

\section{Aging}

It is common to observe impairments in cardiovascular autonomic function resulting from the aging process, especially in women, as aging is marked by ovarian failure, exponentially reducing the production of hormones, especially estrogens, which play a cardiovascular protective role. Clinical and experimental studies have shown that aging is characterized by increases in BPV and reductions in HRV and baroreflex sensitivity. ${ }^{41-44}$ In a previous study, the decrease in low-frequency (LF; 0.04-0.15 Hz) and high-frequency (HF; $0.15-0.5 \mathrm{~Hz}$ ) oscillations of $\mathrm{HRV}$, when investigated through frequency domain analysis (spectral analysis), indicated reduction in cardiac vagal modulation in elderly individuals. ${ }^{45}$ The vagal autonomic component is responsible for the HF HRV oscillations and also in part for the LF oscillations. ${ }^{1,2,4}$ However, the reduction in HRV LF oscillations also suggests a decrease in cardiac sympathetic modulation, ${ }^{4}$ although studies have shown that aging is associated with increased levels of plasma catecholamines ${ }^{46,47}$ and peripheral sympathetic nervous activity. ${ }^{48,49}$ Thus, a plausible explanation for the alterations in cardiac autonomic modulation is the impairment in baroreflex sensitivity. Studies have shown that HRV LF oscillations are mediated by the sympathetic 
autonomic component and depend on the integrity of the baroreflex arc. ${ }^{4,50}$ Further, HRV analysis assesses autonomic modulation of the heart and not cardiac autonomic activity. ${ }^{51}$ This is important because while cardiac sympathetic and vagal activity are associated with the autonomic nervous inflow of both components to the heart, resulting in an increase (sympathetic activity) or decrease (vagal activity) in heart rate, sympathetic and vagal autonomic modulation are associated with the instantaneous (phasic) variations in heart rate induced by both, however at different frequencies of occurrence.

Moreover, it is possible that the increase in BPV often found in elderly patients is largely due to the aging process. This statement is based on clinical and experimental studies in elderly patients, which demonstrated that increased BPV in patients with hypertension is associated with greater target organ damage and increased occurrence of cardiovascular events. ${ }^{43,52}$ The cause of the increase in BPV has been widely discussed; however, some studies indicate vascular sympathetic hyperactivity as the genesis of this phenomenon. $^{43,53}$ Other studies have also attributed the reduction in baroreflex sensitivity as a determining cause. It has been postulated that the reduced inhibition of vasomotor centers, resulting from the adaptation of baroreceptors, is responsible for the increase in sympathetic activity and perpetuation of hypertension in some cases. ${ }^{54}$ The other causes involving aging include the evident decrease in compliance and distensibility of the arterial system associated with endothelial involvement. ${ }^{55,56}$ Aging is also a risk factor for the development of chronic degenerative diseases as advancing age promotes structural and functional changes in the heart, vessels, and other organs. ${ }^{57,58}$

\section{Heart Rate Variability and Cardiovascular Fitness}

Current knowledge on cardiovascular disease has triggered a search for ways to improve regulation of cardiac autonomic modulation. Amongst these, the role of regular physical exercise to improve cardiovascular fitness has been increasingly highlighted. It promotes beneficial cardiac autonomic adjustments; moreover, a decreased level of cardiovascular fitness is associated with an increased risk of morbidity and mortality, even in the absence of other risk factors. ${ }^{59-62}$ In this sense, individuals with moderate to high cardiovascular fitness resulting from regular physical exercise, especially aerobic exercise, have a low risk of mortality from chronic degenerative diseases, especially cardiovascular and metabolic diseases. ${ }^{59-64}$ However, there seems to be no consensus in the literature on the influence of the level of cardiovascular fitness and cardiac autonomic control in healthy individuals. Some studies have found that cardiovascular fitness does not exert any effect on heart rate variability (HRV) in healthy young and middle-aged individuals. ${ }^{65-70}$ These studies hypothesized that autonomic cardiovascular control in healthy individuals operates in an "optimal" condition; thus, physical training would have no additional effect, other than the already known cardiovascular effects, such as reduction in heart rate at rest and faster heart rate recovery. ${ }^{71}$ On the other hand, some authors defend the use of HRV analysis to aid in the prognosis of stress and cardiovascular conditioning in athletes, directing the prescription of physical training. ${ }^{72-75}$ The evaluation and monitoring of performance counters during the training cycle may allow individualization of the workload whenever necessary, in order to obtain the highest possible performance of the athlete. ${ }^{76,77}$ At the same time, they can be effective in diagnosing phenomena called overreaching (temporary loss of performance that can be reversed with adequate recovery periods) and overtraining (state of severe and chronic fatigue caused by an imbalance between training, competition, and recovery). ${ }^{78}$ To this end, further studies are required on the effects of cardiovascular fitness on the autonomic modulation of HRV in healthy individuals.

\section{Cardiovascular Diseases}

However, as noted above, individuals with chronic degenerative diseases often present with impairments in autonomic modulation, resulting in a reduction in HRV. Interestingly, when subjected to a physical training program, mainly aerobic, these same individuals tend to present an increase in HRV (Figure 1), which is often accompanied by a reduction in hemodynamic and metabolic parameters. ${ }^{23,79,80}$ The improvement in HRV due to the increase in cardiovascular fitness may involve multiple factors, such as local and systemic adaptations. Foremost is the obvious adaptation most commonly observed in the morphology and functionality of the heart resulting in a better performance, and consequently, a lesser dependence on the sympathetic autonomic component. This observation is based on experimental and clinical studies that demonstrated a decrease in adverse cardiac remodeling and cardiac fibrosis, in addition to the regulation of $\beta$ adrenergic receptor expression, increased cardiac output, 
and improved contractility after an aerobic exercise training protocol. ${ }^{81-87}$

A reduction in circulating blood levels of catecholamines and angiotensin II has also been observed, ${ }^{24,25,83,88}$ in addition to the recovery of endothelial function; increasing bioavailability of nitric oxide (NO); reduction of proinflammatory cytokines, such as TNF- $\alpha$ and IL-6; and low oxidative stress. ${ }^{79,89-95}$ Another important effect of physical training seems to involve central neural adaptations; autonomic adjustments also derive from effects on central neural nuclei of cardiovascular control, resulting in increased vagal drive and/or a decrease in sympathetic drive and improvement in baroreflex sensitivity. ${ }^{89,96-102}$ Thus, the sum of local and systemic effects associated with increased cardiovascular fitness results in a more adequate cardiac autonomic modulation, characterized by an increase in HRV.

\section{Metabolic Diseases}

Similarly, in individuals with cardiovascular diseases, an increase in cardiovascular fitness through physical exercise is essential for the control and treatment of metabolic diseases. Several studies have indicated a positive relationship between controlled metabolic parameters, cardiovascular fitness, and autonomic modulation of HRV. ${ }^{103-106}$ Among these effects, the improvement in glucose metabolism associated with an increase in insulin sensitivity stands out. Other important effects have also been observed, such as reduction in fat mass, improvement in body composition, and reduction in inflammatory and oxidative stress markers. ${ }^{104,105,107-110}$ Consequently, all these beneficial effects resulting from the increase in cardiovascular fitness can contribute to the improvement on autonomic modulation of HRV. That is, increased cardiovascular fitness results in a better balance of cardiac autonomic modulation, characterized by increased vagal modulation and/or reduced sympathetic modulation, ${ }^{106,109,111}$ which has been observed in patients with major complications and comorbidities due to diabetes. ${ }^{112,113}$ Furthermore, all these benefits of better cardiovascular fitness, in addition to contributing to the regulation of the autonomic modulation of HRV, also contribute to the prevention of cardiovascular diseases and improvement in quality of life in general.

\section{Aging}

With advancing age, it is common to observe adjustments in different body systems. Regarding the cardiovascular system, adjustments in autonomic regulation of HRV are characterized by a prominent reduction. Increased cardiovascular fitness through regular exercise provides important cardiovascular and metabolic benefits to the elderly, such as reduced blood pressure, improved insulin sensitivity, improved endothelial function, and reduced oxidative stress. ${ }^{114,115}$ In addition, physical exercise, especially aerobic exercise, has been shown to be beneficial in increasing HRV in these individuals, mainly by increasing parameters that correspond to the vagal autonomic component. ${ }^{116-120}$ In this regard, studies suggest that increased cardiovascular fitness through regular exercise throughout the life of an individual can mitigate the effects of aging on vagal modulation. $^{121-124}$ However, there is a demand for further investigation, as not all studies report this relationship. ${ }^{125-129}$ Another important effect of greater cardiovascular fitness is its association with the improvement and/or maintenance of cognitive skills. ${ }^{130-132}$ We also highlight the fundamental role of better cardiovascular fitness in the maintenance of health and well-being during aging.

In this context, the analysis of HRV can be used as a form of clinical assessment of cardiovascular homeostasis, which is a predictor of cardiovascular mortality, and in the prescription of physical training, since this approach provides information on the integrity of the autonomic function and possible disorders of the autonomic modulation of the heart due to health conditions, advancing age, and level of cardiovascular fitness. ${ }^{4,8,133-136}$

\section{Cautions with Using HRV Analysis}

There is no doubt about the importance of analyzing the variability of intervals between heartbeats as an assessment that allows the identification of the physiological mechanisms that guide the regulation of heart rate, such as sympathetic and vagal autonomic components. However, standardization of methodologies that permit reproducibility between evaluators/researchers is essential, especially when it comes to a widely disseminated tool in the scientific community and in clinical practice. In this case, the experimental design is perhaps more important than the tool used in the evaluation. In our literature review, we found widespread use of HRV analysis but lack of details about the methodology employed. Below, we discuss the two main factors: sex and age.

For many years, men and women were included in the same study group for HRV analysis. Now, we know that this can introduce an important bias in the results. ${ }^{127,137}$ More recent studies have shown that women before menopause have lower oscillations of the sympathetic autonomic 

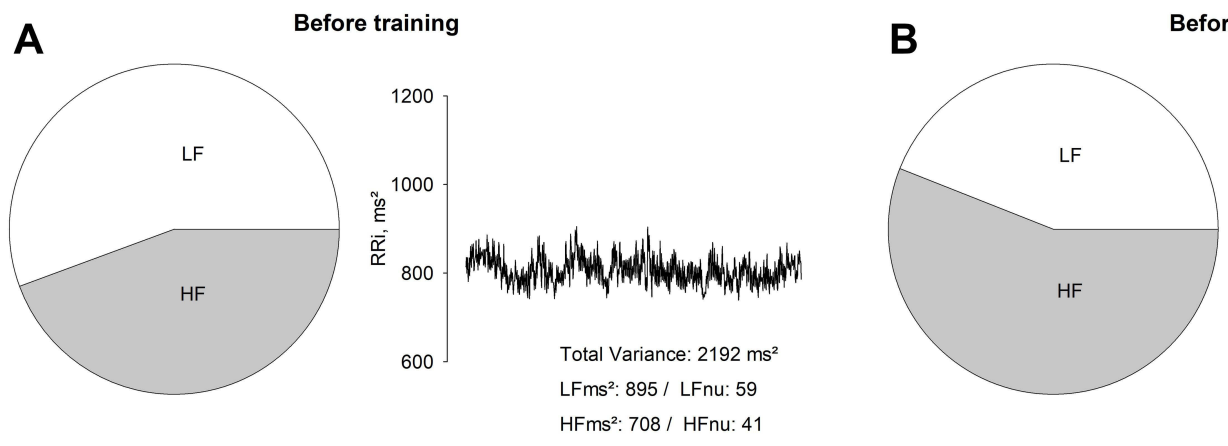

Before training

HFms': 708 / HFnu: 41
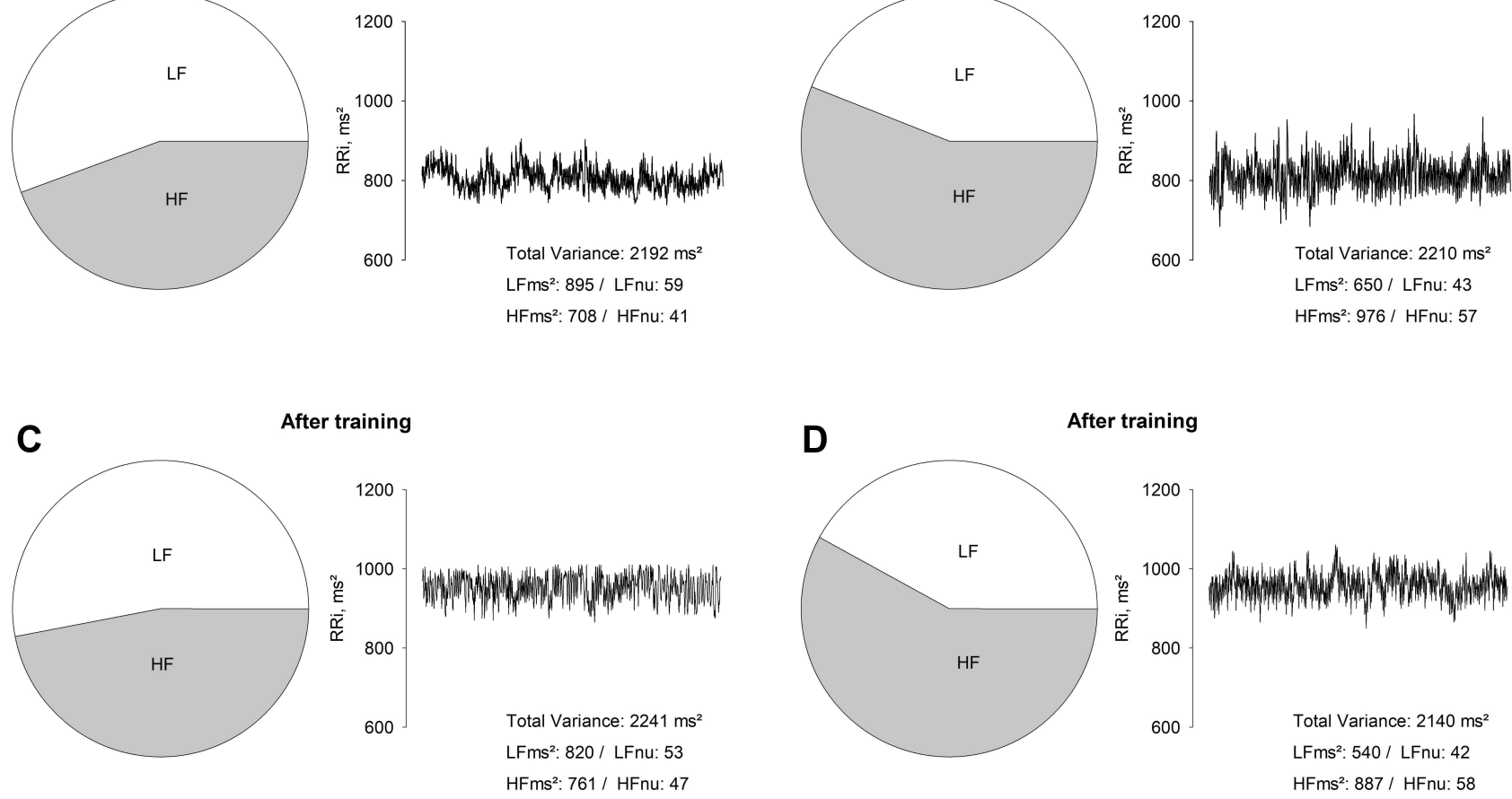

Figure 2 Representative illustration of heart rate variability parameters through spectral analysis in normotensive men (A and $\mathbf{C})$ and women (B and $\mathbf{D})$ obtained in our laboratory, before and after 16 weeks of aerobic physical training. The RR intervals (RRi) in absolute units ( $\mathrm{ms}^{2}$ ) time series are illustrated by the line chart and was used the low-frequency (LF) and high-frequency (HF) bands in normalized units (nu) to indicated the relationship between autonomic modulation balance by the pie chart.

component and greater oscillations of the cardiac vagal autonomic component when compared to age-matched men (Figure 2), ${ }^{69,70,138,139}$ including individuals with a history of systemic arterial hypertension. ${ }^{26}$

The causes of these differences have not been fully elucidated; however, the beneficial effect of ovarian hormones on cardiovascular autonomic control is a very important variable, since estrogens seem to be able to increase the vagal influence on the heart, in addition to reducing the sympathetic influence on the heart and vascular beds. ${ }^{140-142}$ These effects are consistent with other studies that observed autonomic impairments resulting from ovarian failure, such as a reduction in HRV and baroreflex sensitivity. ${ }^{143-146}$ These studies also discuss the mechanisms involved in this process, mainly the influence of estrogen on the different sites involved in cardiac autonomic regulation, including central neural sites, in addition to interfering with the expression and/or responsiveness of $\beta$-adrenergic receptors that affect the cardiac contractile response. ${ }^{81,147-150}$

Similar to the female sex hormones, androgens also appear to influence cardiac autonomic control, and some studies have shown a close relationship between these hormones and the autonomic nervous system. ${ }^{151-153}$ Thus, testosterone levels in men, as well as estrogen levels in women, are important factors that might determine the differences in cardiovascular autonomic control of the sexes.

Furthermore, it is very common to find studies that present a wide age range in experimental protocols. This is a mistake because with aging, there is a tendency for reduction in HRV. In this case, the inclusion of younger age groups may overestimate the values of older age groups, and vice versa. Another important point is that the responses observed to a particular procedure or physical training in a younger group may not be reproduced in an older group.

\section{Conclusions}

In summary, there is a close relationship between cardiovascular fitness and HRV. This relationship was more evident in patients with cardiovascular and metabolic diseases and in aging, especially in those whose 
cardiovascular fitness and HRV were below the predicted values for age and sex. The challenge is to develop techniques and interpretation of increasingly accurate data, as well as standardizing the application of these techniques.

\section{Highlights}

1. Autonomic modulation parameters of heart rate variability are considered predictors of morbidity and mortality;

2. Heart rate variability is often impaired in patients with cardiovascular and metabolic diseases;

3. Aging reduces heart rate variability preponderantly;

4. Aerobic exercise is essential to attenuate autonomic impairments;

5. There is no consensus that aerobic exercise training potentiates cardiovascular autonomic modulation in healthy individuals;

6. Women in reproductive age and age-matched men show distinct regulations in cardiac autonomic modulation;

7. Heart rate or pulse intervals records requires strict criteria.

\section{Disclosure}

The authors report no conflicts of interest in this work.

\section{References}

1. Akselrod S, Gordon D, Ubel F, Shannon D, Berger A, Cohen R. Power spectrum analysis of heart rate fluctuation: a quantitative probe of beat-to-beat cardiovascular control. Science. 1981;213(4504):22 0-222. doi:10.1126/science.6166045

2. Pomeranz B, Macaulay RJ, Caudill MA, et al. Assessment of autonomic function in humans by heart rate spectral analysis. Am J Physiol Heart Circulat Physiol. 1985;248(1):H151-H153. doi:10.1152/ ajpheart.1985.248.1.H151

3. Malliani A, Pagani M, Lombardi F, Cerutti S. Cardiovascular neural regulation explored in the frequency domain. Circulation. 1991;84 (2):482-492. doi:10.1161/01.cir.84.2.482

4. Task Force of the European Society of Cardiology and the North American Society of Pacing and Electrophysiology. Heart rate variability: standards of measurement, physiological interpretation and clinical use. Circulation. 1996;93(5):1043-1065. doi:10.1161/01.CIR.93.5.1043

5. Parati G, Ulian L, Santucciu C, et al. Clinical value of blood pressure variability. Blood Press Suppl. 1997;2:91-96.

6. Stauss HM. Identification of blood pressure control mechanisms by power spectral analysis: BP control mechanisms and spectral analysis. Clin Exp Pharmacol Physiol. 2007;34(4):362-368. doi:10.1111/ j.1440-1681.2007.04588.x

7. Chen Y, Yu Y, Zou W, Zhang M, Wang Y, Gu Y. Association between cardiac autonomic nervous dysfunction and the severity of coronary lesions in patients with stable coronary artery disease. $J$ Int Med Res. 2018;46(9):3729-3740. doi:10.1177/0300060518778416

8. Fang S-C, Wu Y-L, Tsai P-S. Heart rate variability and risk of all-cause death and cardiovascular events in patients with cardiovascular disease: a meta-analysis of cohort studies. Biol Res Nurs. 2020;22(1):45-56. doi:10.1177/1099800419877442
9. Hon EH, Lee ST. Electronic evaluation of the fetal heart rate. VIII. patterns preceding fetal death, further observations. $\mathrm{Am}$ J Obstet Gynecol. 1963;87:814-826.

10. Murray A, Ewing DJ, Campbell IW, Neilson JM, Clarke BF. RR interval variations in young male diabetics. Heart. 1975;37 (8):882-885. doi:10.1136/hrt.37.8.882

11. Wolf MM, Varigos GA, Hunt D, Sloman JG. Sinus arrhythmia in acute myocardial infarction. Med J Aust. 1978;2(2):52-53. doi:10.5694/j.1326-5377.1978.tb131339.x

12. Kleiger RE, Miller JP, Bigger JT, Moss AJ. Decreased heart rate variability and its association with increased mortality after acute myocardial infarction. Am J Cardiol. 1987;59(4):256-262. doi:10.1016/0002-9149(87)90795-8

13. Malik M, Farrell T, Cripps T, Camm AJ. Heart rate variability in relation to prognosis after myocardial infarction: selection of optimal processing techniques. Eur Heart J. 1989;10(12):1060-1074. doi:10.1093/oxfordjournals.eurheartj. a059428

14. Wu H-T, Soliman EZ. A new approach for analysis of heart rate variability and QT variability in long-term ECG recording. Bio Med Eng OnLine. 2018;17(1):54. doi:10.1186/s12938-0180490-8

15. Porta A, Tobaldini E, Guzzetti S, Furlan R, Montano N, GnecchiRuscone T. Assessment of cardiac autonomic modulation during graded head-up tilt by symbolic analysis of heart rate variability. Am J Physiol Heart Circ Physiol. 2007;293(1):H702-H708. doi:10.1152/ajpheart.00006.2007

16. Beckers F, Ramaekers D, Aubert AE. Approximate entropy of heart rate variability: validation of methods and application in heart failure. Cardiovasc Eng. 2001;1(4):177-182. doi:10.1023/ A:1015212328405

17. Thayer JF, Yamamoto SS, Brosschot JF. The relationship of autonomic imbalance, heart rate variability and cardiovascular disease risk factors. Int $J$ Cardiol. 2010;141(2):122-131. doi:10. 1016/j.ijcard.2009.09.543

18. Palatini P, Julius S. The role of cardiac autonomic function in hypertension and cardiovascular disease. Curr Sci Inc. 2009;11 (3):199-205. doi:10.1007/s11906-009-0035-4

19. Mancia G, Grassi G. The autonomic nervous system and hypertension. Circ Res. 2014;114(11):1804-1814. doi:10.1161/ CIRCRESAHA.114.302524

20. Floras JS. Sympathetic nervous system activation in human heart failure. J Am Coll Cardiol. 2009;54(5):375-385. doi:10.1016/j. jacc.2009.03.061

21. Florea VG, Cohn JN. The autonomic nervous system and heart failure. Circ Res. 2014;114(11):1815-1826. doi:10.1161/ CIRCRESAHA.114.302589

22. Zekios KC, Mouchtouri E-T, Lekkas P, Nikas DN, Kolettis TM. Sympathetic activation and arrhythmogenesis after myocardial infarction: where do we stand? JCDD. 2021;8(5):57. doi:10. 3390/jcdd8050057

23. Besnier F, Labrunée M, Pathak A, et al. Exercise training-induced modification in autonomic nervous system: an update for cardiac patients. Ann Phys Rehabil Med. 2017;60(1):27-35. doi:10.1016/ j.rehab.2016.07.002

24. Koba S. Angiotensin II, oxidative stress, and sympathetic nervous system hyperactivity in heart failure. Yonago Acta Med. 2018;61 (2):103-109. doi:10.33160/yam.2018.06.002

25. Zucker IH, Schultz HD, Patel KP, Wang H. Modulation of angiotensin II signaling following exercise training in heart failure. $\mathrm{Am}$ J Physiol Heart Circulat Physiol. 2015;308(8):H781-H791. doi:10.1152/ajpheart.00026.2015

26. Philbois SV, Facioli TP, Gastaldi AC, et al. Important differences between hypertensive middle-aged women and men in cardiovascular autonomic control—a critical appraisal. Biol Sex Differ. 2021;12(1):11. doi:10.1186/s13293-020-00355-y 
27. Cozza IC, Di Sacco THR, Mazon JH, et al. Physical exercise improves cardiac autonomic modulation in hypertensive patients independently of angiotensin-converting enzyme inhibitor treatment. Hypertens Res. 2012;35(1):82-87. doi:10.1038/hr.2011.162

28. Carthy ER. Autonomic dysfunction in essential hypertension: a systematic review. Ann Med Surg. 2014;3(1):2-7. doi:10.1016/ j.amsu.2013.11.002

29. Jarczok MN, Li J, Mauss D, Fischer JE, Thayer JF. Heart rate variability is associated with glycemic status after controlling for components of the metabolic syndrome. Int J Cardiol. 2013;167 (3):855-861. doi:10.1016/j.ijcard.2012.02.002

30. Kangas P, Tikkakoski A, Uitto M, et al. Metabolic syndrome is associated with decreased heart rate variability in a sex-dependent manner: a comparison between 252 men and 249 women. Clin Physiol Funct Imaging. 2019;39(2):160-167. doi:10.1111/cpf.12551

31. Benichou T, Pereira B, Mermillod M, et al. Heart rate variability in type 2 diabetes mellitus: a systematic review and meta-analysis. Malik RA, ed. PLoS One. 2018;13(4):e0195166. doi:10.1371/ journal.pone. 0195166

32. Kurajoh M, Koyama H, Kadoya M, et al. Plasma leptin level is associated with cardiac autonomic dysfunction in patients with type 2 diabetes: HSCAA study. Cardiovasc Diabetol. 2015;14 (1):117. doi:10.1186/s12933-015-0280-6

33. Koenig J, Windham BG, Ferrucci L, et al. Association strength of three adiposity measures with autonomic nervous system function in apparently healthy employees. $J$ Nutr Health Aging. 2015;19 (9):879-882. doi:10.1007/s12603-015-0508-x

34. Franz R, Maturana MA, Magalhães JA, Moraes RS, Spritzer PM. Central adiposity and decreased heart rate variability in postmenopause: a cross-sectional study. Climacteric. 2013;16 (5):576-583. doi:10.3109/13697137.2012.745123

35. Lambert EA, Straznicky NE, Dixon JB, Lambert GW. Should the sympathetic nervous system be a target to improve cardiometabolic risk in obesity? Am J Physiol Heart Circulat Physiol. 2015;309(2):H244-H258. doi:10.1152/ajpheart.00096.2015

36. Paolisso G, Manzella D, Montano N, Gambardella A, Varricchio M. Plasma leptin concentrations and cardiac autonomic nervous system in healthy subjects with different body weights. J Clin Endocrinol Metab. 2000;85(5):1810-1814. doi:10.1210/jcem.85.5.6511

37. Arnold AC, Diz DI. Endogenous leptin contributes to baroreflex suppression within the solitary tract nucleus of aged rats. $\mathrm{Am}$ J Physiol Heart Circulat Physiol. 2014;307(11):H1539-H1546. doi:10.1152/ajpheart.00282.2014

38. Brunner EJ, Hemingway H, Walker BR, et al. Adrenocortical, autonomic, and inflammatory causes of the metabolic syndrome: nested case-control study. Circulation. 2002;106(21):2659-2665. doi:10.1161/01.CIR.0000038364.26310.BD

39. Wegeberg A-ML, Okdahl T, Fløyel T, et al. Circulating inflammatory markers are inversely associated with heart rate variability measures in type 1 diabetes. Mediators Inflamm. 2020;2020:1-10. doi:10.1155/2020/3590389

40. Bhati P, Moiz JA, Menon GR, Hussain ME. Does resistance training modulate cardiac autonomic control? A systematic review and meta-analysis. Clin Auton Res. 2019;29(1):75-103. doi:10.1007/s10286-018-0558-3

41. Ferrari AU, Radaelli A, Centola M. Invited review: aging and the cardiovascular system. J Appl Physiol. 2003;95(6):2591-2597. doi:10.1152/japplphysiol.00601.2003

42. Veerman DP, Imholz BP, Wieling W, Karemaker JM, van Montfrans GA. Effects of aging on blood pressure variability in resting conditions. Hypertension. 1994;24(1):120-130. doi:10.1161/01. hyp.24.1.120

43. Parati G, Frattola A, Di Rienzo M, Castiglioni P, Mancia G. Broadband spectral analysis of blood pressure and heart rate variability in very elderly subjects. Hypertension. 1997;30 (4):803-808. doi:10.1161/01.HYP.30.4.803
44. Lavi S, Nevo O, Thaler I, et al. Effect of aging on the cardiovascular regulatory systems in healthy women. Am J Physiol Regul Integr Comp Physiol. 2007;292(2):R788-R793. doi:10.1152/ ajpregu.00352.2006

45. Wieling W, van Brederode JFM, de Rijk LG, Borst C, Dunning AJ. Reflex control of heart rate in normal subjects in relation to age: a data base for cardiac vagal neuropathy. Diabetologia. 1982;22(3):163-166. doi:10.1007/BF00283745

46. Rubin PC, Scott PJW, McLEAN K, Reid JL. Noradrenaline release and clearance in relation to age and blood pressure in man. Eur J Clin Invest. 1982;12(2):121-125. doi:10.1111/j.13652362.1982.tb00948.x

47. Esler MD, Turner AG, Kaye DM, et al. Aging effects on human sympathetic neuronal function. Am J Physiol. 1995;268(1 Pt 2): R278-285. doi:10.1152/ajpregu.1995.268.1.R278

48. Iwase S, Mano T, Watanabe T, Saito M, Kobayashi F. Age-related changes of sympathetic outflow to muscles in humans. J Gerontol. 1991;46(1):M1-5. doi:10.1093/geronj/46.1.m1

49. Ng AV, Callister R, Johnson DG, Seals DR. Age and gender influence muscle sympathetic nerve activity at rest in healthy humans. Hypertension. 1993;21(4):498-503. doi:10.1161/01.HYP.21.4.498

50. Malpas SC, Ninomiya I. The amplitude and periodicity of synchronized renal sympathetic nerve discharges in anesthetized cats: differential effect of baroreceptor activity. J Auton Nerv Syst. 1992;40(3):189-198. doi:10.1016/0165-1838(92)90200-Z

51. Parati G, Mancia G, Rienzo MD, Castiglioni P. Point: counterpoint: cardiovascular variability is/is not an index of autonomic control of circulation. J Appl Physiol. 2006;101(2):676-682. doi:10.1152/japplphysiol.00446.2006

52. Miao C-Y, Xie -H-H, Zhan L-S, Su D-F. Blood pressure variability is more important than blood pressure level in determination of end-organ damage in rats. $J$ Hypertens. 2006;24 (6):1125-1135. doi:10.1097/01.hjh.0000226203.57818.88

53. Sollers JJ, Merritt MM, Silver RA, Evans MK, Zonderman AB, Thayer JF. Understanding blood pressure variability: spectral indices as a function of gender and age. Biomed Sci Instrum. 2005;41:43-47.

54. Shepherd JT. Increased systemic vascular resistance and primary hypertension: the expanding complexity. J Hypertens Suppl. 1990;8(7):S15-S27.

55. Tanaka H, Dinenno FA, Monahan KD, Clevenger CM, DeSouza CA, Seals DR. Aging, habitual exercise, and dynamic arterial compliance. Circulation. 2000;102(11):1270-1275. doi:10.1161/01.CIR.102.11.1270

56. Sugawara J, Komine H, Hayashi K, et al. Systemic $\alpha$-adrenergic and nitric oxide inhibition on basal limb blood flow: effects of endurance training in middle-aged and older adults. Am J Physiol Heart Circulat Physiol. 2007;293(3):H1466-H1472. doi:10.1152/ ajpheart.00273.2007

57. Paneni F, Diaz Cañestro C, Libby P, Lüscher TF, Camici GG. The aging cardiovascular system. J Am Coll Cardiol. 2017;69 (15):1952-1967. doi:10.1016/j.jacc.2017.01.064

58. De Meersman RE, Stein PK. Vagal modulation and aging. Biol Psychol. 2007;74(2):165-173. doi:10.1016/j.biopsycho.2006.04. 008

59. Carnethon MR. Prevalence and cardiovascular disease correlates of low cardiorespiratory fitness in adolescents and adults. JAMA. 2005;294(23):2981. doi:10.1001/jama.294.23.2981

60. Kodama S. Cardiorespiratory fitness as a quantitative predictor of all-cause mortality and cardiovascular events in healthy men and women: a meta-analysis. JAMA. 2009;301(19):2024. doi:10.1001/ jama.2009.681

61. Lee D-C, Sui X, Ortega FB, et al. Comparisons of leisure-time physical activity and cardiorespiratory fitness as predictors of all-cause mortality in men and women. $\mathrm{Br} J$ Sports Med. 2011;45(6):504-510. doi:10.1136/bjsm.2009.066209 
62. Myers J, Kokkinos P, Chan K, et al. Cardiorespiratory fitness and reclassification of risk for incidence of heart failure: the veterans exercise testing study. Circ Heart Failure. 2017;10(6). doi:10. 1161/CIRCHEARTFAILURE.116.003780

63. Virani SS, Alonso A, Benjamin EJ, et al. Heart disease and stroke statistics-2020 update: a report from the American Heart Association. Circulation. 2020;141(9):e139-e596. doi:10.1161/ CIR.0000000000000757

64. Kaminsky LA, Arena R, Ellingsen $\varnothing$, et al. Cardiorespiratory fitness and cardiovascular disease - the past, present, and future. Prog Cardiovasc Dis. 2019;62(2):86-93. doi:10.1016/j.pcad.20 19.01 .002

65. Hautala AJ, Mäkikallio TH, Kiviniemi A, et al. Cardiovascular autonomic function correlates with the response to aerobic training in healthy sedentary subjects. Am J Physiol Heart Circulat Physiol. 2003;285(4):H1747-H1752. doi:10.1152/ajpheart.00202. 2003

66. Shin K, Minamitani H, Onishi S, Yamazaki H, Lee M. Autonomic differences between athletes and nonathletes: spectral analysis approach. Med Sci Sports Exer. 1997;29(11):1482-1490. doi:10.1097/00005768-199711000-00015

67. Soares-Miranda L, Sandercock G, Valente H, Vale S, Santos R, Mota J. Vigorous physical activity and vagal modulation in young adults. Eur J Cardiovasc Preven Rehabil. 2009;16(6):705-711. doi:10.1097/HJR.0b013e3283316cd1

68. Kingsley JD, Figueroa A. Acute and training effects of resistance exercise on heart rate variability. Clin Physiol Funct Imaging. 2016;36(3):179-187. doi:10.1111/cpf.12223

69. Dutra SGV, Pereira APM, Tezini GC, Mazon JH, Martins-Pinge MC, Souza HCD. Cardiac autonomic modulation is determined by gender and is independent of aerobic physical capacity in healthy subjects. PLoS One. 2013;8(10):e77092. doi:10.1371/ journal.pone.0077092

70. Facioli TP, Gastaldi AC, Dutra SGV, et al. The blood pressure variability and baroreflex sensitivity in healthy participants are not determined by sex or cardiorespiratory fitness. Blood Press Monit. 2018;23(5):260-270. doi:10.1097/MBP.000000000000 0338

71. Facioli TP, Philbois SV, Gastaldi AC, et al. Study of heart rate recovery and cardiovascular autonomic modulation in healthy participants after submaximal exercise. Sci Rep. 2021;11 (1):3620. doi:10.1038/s41598-021-83071-w

72. Tulppo MP, Hautala AJ, Mäkikallio TH, et al. Effects of aerobic training on heart rate dynamics in sedentary subjects. J Appl Physiol. 2003;95(1):364-372. doi:10.1152/japplphysiol.00751.2002

73. Garet M, Tournaire N, Roche F, et al. Individual interdependence between nocturnal ANS activity and performance in swimmers. Med Sci Sports Exerc. 2004;2112-2118. doi:10.1249/01. MSS.0000147588.28955.48

74. Kiviniemi AM, Hautala AJ, Mäkikallio TH, Seppänen T, Huikuri HV, Tulppo MP. Cardiac vagal outflow after aerobic training by analysis of high-frequency oscillation of the R-R interval. Eur J Appl Physiol. 2006;96(6):686-692. doi:10.1007/ s00421-005-0130-4

75. Kiviniemi AM, Hautala AJ, Kinnunen H, Tulppo MP. Endurance training guided individually by daily heart rate variability measurements. Eur J Appl Physiol. 2007;101(6):743-751. doi:10.1007/s00421-007-0552-2

76. Hoffman JR, Kang J, Ratamess NA, Faigenbaum AD. Biochemical and hormonal responses during an intercollegiate football season. Med Sci Sports Exerc. 2005;37(7):1237-1241. doi:10.1249/01.mss.0000170068.97498.26

77. Mazon J, Gastaldi A, Di Sacco T, Cozza I, Dutra S, Souza H. Effects of training periodization on cardiac autonomic modulation and endogenous stress markers in volleyball players. Scand J Med Sci Sports. 2013;23(1):114-120. doi:10.1111/j.1600-0838.2011.01357.x
78. Baumert M, Brechtel L, Lock J, et al. Heart rate variability, blood pressure variability, and baroreflex sensitivity in overtrained athletes. Clin J Sport Med. 2006;16(5):412-417. doi:10.1097/01. jsm.0000244610.34594.07

79. Pearson MJ, Smart NA. Effect of exercise training on endothelial function in heart failure patients: a systematic review meta-analysis. Int $J$ Cardiol. 2017;231:234-243. doi:10.1016/j. ijcard.2016.12.145

80. Routledge FS, Campbell TS, McFetridge-Durdle JA, Bacon SL. Improvements in heart rate variability with exercise therapy. Can $J$ Cardiol. 2010;26(6):303-312. doi:10.1016/s0828-282x(10) 70395-0

81. Felix ACS, Dutra SGV, Tezini GC, Simões MV, De Souza HCD. Aerobic physical training increases contractile response and reduces cardiac fibrosis in rats subjected to early ovarian hormone deprivation. J Appl Physiol. 2015;118(10):1276-1285. doi:10. 1152/japplphysiol.00483.2014

82. Jia -L-L, Kang Y-M, Wang F-X, et al. Exercise training attenuates hypertension and cardiac hypertrophy by modulating neurotransmitters and cytokines in hypothalamic paraventricular nucleus. PLoS One. 2014;9(1):e85481. doi:10.1371/journal.pone.0085481

83. Acanfora D, Scicchitano P, Casucci G, et al. Exercise training effects on elderly and middle-age patients with chronic heart failure after acute decompensation: a randomized, controlled trial. Int J Cardiol. 2016;225:313-323. doi:10.1016/j.ijcard.20 16.10 .026

84. Meyer M, McEntee RK, Nyotowidjojo I, Chu G, LeWinter MM. Relationship of exercise capacity and left ventricular dimensions in patients with a normal ejection fraction. an exploratory study. Singla DK, ed. PLoS One. 2015;10(3):e0119432. doi:10.1371/ journal.pone.0119432

85. MacDonnell SM, Kubo H, Crabbe DL, et al. Improved myocardial $\beta$-adrenergic responsiveness and signaling with exercise training in hypertension. Circulation. 2005;111(25):3420-3428. doi:10.1161/CIRCULATIONAHA.104.505784

86. de Almeida SA, Claudio ERG, Mengal VF, et al. Exercise training reduces cardiac dysfunction and remodeling in ovariectomized rats submitted to myocardial infarction. Gupta $\mathrm{S}$, ed. PLoS One. 2014;9(12):e115970. doi:10.1371/journal.pone.0115 970

87. Leosco D, Rengo G, Iaccarino G, et al. Exercise promotes angiogenesis and improves $\beta$-adrenergic receptor signalling in the postischaemic failing rat heart. Cardiovasc Res. 2008;78(2):385-394. doi: $10.1093 / \mathrm{cvr} / \mathrm{cvm} 109$

88. Townend JN, Al-Ani M, West JN, Littler WA, Coote JH. Modulation of cardiac autonomic control in humans by angiotensin II. Hypertension. 1995;25(6):1270-1275. doi:10.1161/01. HYP.25.6.1270

89. Zheng H, Li Y-F, Cornish KG, Zucker IH, Patel KP. Exercise training improves endogenous nitric oxide mechanisms within the paraventricular nucleus in rats with heart failure. Am J Physiol Heart Circulat Physiol. 2005;288(5):H2332-H2341. doi:10.1152/ ajpheart.00473.2004

90. Kingwell BA. Nitric oxide as a metabolic regulator during exercise: effects of training in health and disease. Clin Exp Pharmacol Physiol. 2000;27(4):239-250. doi:10.1046/j.1440-1681.2000.03 232.x

91. Smart NA, Steele M. The effect of physical training on systemic proinflammatory cytokine expression in heart failure patients: a systematic review: physical training and cytokine levels. Congest Heart Failure. 2011;17(3):110-114. doi:10.1111/j.17517133.2011.00217.x

92. Papaioannou V, Pneumatikos I, Maglaveras N. Association of heart rate variability and inflammatory response in patients with cardiovascular diseases: current strengths and limitations. Front Physiol. 2013;4. doi:10.3389/fphys.2013.00174 
93. Kishi T, Hirooka Y, Katsuki M, et al. Exercise training causes sympathoinhibition through antioxidant effect in the rostral ventrolateral medulla of hypertensive rats. Clin Exp Hypertens. 2012;34(4):278-283. doi:10.3109/10641963.2012.681084

94. Zanchi NE, Bechara LRG, Tanaka LY, Debbas V, Bartholomeu T, Ramires PR. Moderate exercise training decreases aortic superoxide production in myocardial infarcted rats. Eur J Appl Physiol. 2008;104(6):1045-1052. doi:10.1007/s00421-008-0861-0

95. Santa-Rosa FA, Shimojo GL, Dias DS, et al. Impact of an active lifestyle on heart rate variability and oxidative stress markers in offspring of hypertensives. Sci Rep. 2020;10(1):12439. doi:10.1038/s41598-020-69104-w

96. Kramer JM, Plowey ED, Beatty JA, Little HR, Waldrop TG. Hypothalamus, hypertension, and exercise. Brain Res Bull. 2000;53(1):77-85. doi:10.1016/S0361-9230(00)00311-7

97. Martins-Pinge MC, Becker LK, Garcia MRL, et al. Attenuated pressor responses to amino acids in the rostral ventrolateral medulla after swimming training in conscious rats. Auto Neurosci. 2005;122(1-2):21-28. doi:10.1016/j.autneu.2005.07. 007

98. de Abreu SB, Lenhard A, Mehanna A, et al. Role of paraventricular nucleus in exercise training-induced autonomic modulation in conscious rats. Auto Neurosci. 2009;148(1-2):28-35. doi:10. 1016/j.autneu.2009.02.007

99. Michelini LC, Stern JE. Exercise-induced neuronal plasticity in central autonomic networks: role in cardiovascular control: exercise-induced CNS plasticity and cardiovascular control. Exp Physiol. 2009;94(9):947-960. doi:10.1113/expphysiol.2009.04 7449

100. Mastelari RB, de Souza HCD, Lenhard A, de Aguiar Corrêa FM, Martins-Pinge MC. Nitric oxide inhibition in paraventricular nucleus on cardiovascular and autonomic modulation after exercise training in unanesthetized rats. Brain Res. 2011;1375:68-76. doi:10.1016/j.brainres.2010.12.049

101. Masson GS, Nair AR, Silva Soares PP, Michelini LC, Francis J. Aerobic training normalizes autonomic dysfunction, HMGB1 content, microglia activation and inflammation in hypothalamic paraventricular nucleus of SHR. Am J Physiol Heart Circulat Physiol. 2015;309(7):H1115-H1122. doi:10.1152/ajpheart.003 49.2015

102. Maida KD, Gastaldi AC, De paula facioli T, de Araújo JE, de Souza HCD. Physical training associated with Enalapril but not to Losartan, results in better cardiovascular autonomic effects. Auton Neurosci. 2017;203:33-40. doi:10.1016/j.autneu.2016.12.002

103. Kaikkonen KM, Korpelainen R, Tulppo MP, et al. Physical activity and aerobic fitness are positively associated with heart rate variability in obese adults. J Phys Act Health. 2014;11 (8):1614-1621. doi:10.1123/jpah.2012-0405

104. Tian Y, Huang C, He Z, Hong P, Zhao J. Autonomic function responses to training: correlation with body composition changes. Physiol Behav. 2015;151:308-313. doi:10.1016/j.physbeh.2015. 07.038

105. Jabbour G, Iancu HD. Supramaximal-exercise training improves heart rate variability in association with reduced catecholamine in obese adults. Front Physiol. 2021;12:654695. doi:10.3389/ fphys.2021.654695

106. Picard M, Tauveron I, Magdasy S, et al. Effect of exercise training on heart rate variability in type 2 diabetes mellitus patients: a systematic review and meta-analysis. Abdelbasset WK, ed. PLoS One. 2021;16(5):e0251863. doi:10.1371/journal.pone.025 1863

107. Park H-Y, Jung W-S, Kim J, Hwang H, Lim K. Twelve weeks of aerobic exercise at the lactate threshold improves autonomic nervous system function, body composition, and aerobic performance in women with obesity. JOMES. 2020;29(1):67-75. doi:10.7570/jomes 19063
108. Sakurai T, Ogasawara J, Shirato K, et al. Exercise training attenuates the dysregulated expression of adipokines and oxidative stress in white adipose tissue. Oxid Med Cell Longev. 2017;2017:1-12. doi:10.1155/2017/9410954

109. Goit RK, Pant BN, Shrewastwa MK. Moderate intensity exercise improves heart rate variability in obese adults with type 2 diabetes. Indian Heart J. 2018;70(4):486-491. doi:10.1016/j. ihj.2017.10.003

110. Kirwan JP, Sacks J, Nieuwoudt S. The essential role of exercise in the management of type 2 diabetes. CCJM. 2017;84(7suppl 1): S15-S21. doi:10.3949/ccjm.84.s1.03

111. Bhati P, Shenoy S, Hussain ME. Exercise training and cardiac autonomic function in type 2 diabetes mellitus: a systematic review. Diabetes Metab Syndr. 2018;12(1):69-78. doi:10.1016/j. dsx.2017.08.015

112. Pagkalos M, Koutlianos N, Kouidi E, Pagkalos E, Mandroukas K, Deligiannis A. Heart rate variability modifications following exercise training in type 2 diabetic patients with definite cardiac autonomic neuropathy. Br J Sports Med. 2007;42(1):47-54. doi:10.1136/bjsm.2007.035303

113. Sridhar B, Haleagrahara N, Bhat R, Kulur AB, Avabratha S, Adhikary P. Increase in the heart rate variability with deep breathing in diabetic patients after 12-month exercise training. Tohoku J Exp Med. 2010;220(2):107-113. doi:10.1620/tjem.220.107

114. Allen J, Morelli V. Aging and exercise. Clin Geriatr Med. 2011;27(4):661-671. doi:10.1016/j.cger.2011.07.010

115. Radak Z, Torma F, Berkes I, et al. Exercise effects on physiological function during aging. Free Radic Biol Med. 2019;132:33-41. doi:10.1016/j.freeradbiomed.2018.10.444

116. Dorey TW, O'Brien MW, Kimmerly DS. The influence of aerobic fitness on electrocardiographic and heart rate variability parameters in young and older adults. Auto Neurosci. 2019;217:66-70. doi:10.1016/j.autneu.2019.01.004

117. Yataco AR, Fleisher LA, Katzel LI. Heart rate variability and cardiovascular fitness in senior athletes. Am J Cardiol. 1997;80 (10):1389-1391. doi:10.1016/S0002-9149(97)00697-8

118. Melo RC, Santos MDB, Silva E, et al. Effects of age and physical activity on the autonomic control of heart rate in healthy men. Braz J Med Biol Res. 2005;38(9):1331-1338. doi:10.1590/S0100879X2005000900007

119. Albinet CT, Boucard G, Bouquet CA, Audiffren M. Increased heart rate variability and executive performance after aerobic training in the elderly. Eur J Appl Physiol. 2010;109 (4):617-624. doi:10.1007/s00421-010-1393-y

120. Raffin J, Barthélémy J-C, Dupré C, et al. Exercise frequency determines heart rate variability gains in older people: a meta-analysis and meta-regression. Sports Med. 2019;49 (5):719-729. doi:10.1007/s40279-019-01097-7

121. Carter JB, Banister EW, Blaber AP. Effect of endurance exercise on autonomic control of heart rate. Sports Med. 2003;33 (1):33-46. doi:10.2165/00007256-200333010-00003

122. Buchheit M, Simon C, Viola AU, Doutreleau S, Piquard F, Brandenberger G. Heart rate variability in sportive elderly: relationship with daily physical activity. Med Sci Sports Exerc. 2004;36(4):601-605. doi:10.1249/01.MSS.0000121956.76237.B5

123. Soares-Miranda L, Sattelmair J, Chaves P, et al. Physical activity and heart rate variability in older adults: the cardiovascular health study. Circulation. 2014;129(21):2100-2110. doi:10.1161/ CIRCULATIONAHA.113.005361

124. Ueno LM, Hamada T, Moritani T. Cardiac autonomic nervous activities and cardiorespiratory fitness in older men. J Gerontol a Biol Sci Med Sci. 2002;57(9):M605-M610. doi:10.1093/gerona/57.9.M605

125. Reland S, Ville NS, Wong S, Gauvrit H, Kervio G, Carre F. Exercise heart rate variability of older women in relation to level of physical activity. J Gerontol a Biol Sci Med Sci. 2003;58(7):B585-B591. doi:10.1093/gerona/58.7.B585 
126. Earnest CP, Blair SN, Church TS. Heart rate variability and exercise in aging women. $J$ Womens Health. 2012;21 (3):334-339. doi:10.1089/jwh.2011.2932

127. Perini R, Fisher N, Veicsteinas A, Pendergast DR. Aerobic training and cardiovascular responses at rest and during exercise in older men and women. Med Sci Sports Exerc. 2002;34 (4):700-708. doi:10.1097/00005768-200204000-00022

128. Verheyden B, Eijnde BO, Beckers F, Vanhees L, Aubert AE. Low-dose exercise training does not influence cardiac autonomic control in healthy sedentary men aged $55-75$ years. J Sports Sci. 2006;24(11):1137-1147. doi:10.1080/02640410500497634

129. McKune AJ, Peters B, Ramklass SS, et al. Autonomic cardiac regulation, blood pressure and cardiorespiratory fitness responses to different training doses over a 12 week group program in the elderly. Arch Gerontol Geriatr. 2017;70:130-135. doi:10.1016/j. archger.2017.01.012

130. Eggenberger P, Annaheim S, Kündig KA, Rossi RM, Münzer T, de Bruin ED. Heart rate variability mainly relates to cognitive executive functions and improves through exergame training in older adults: a secondary analysis of a 6-month randomized controlled trial. Front Aging Neurosci. 2020;12:197. doi:10.3389/fnagi.2020.00197

131. Dupuy O, Bosquet L, Fraser SA, Labelle V, Bherer L. Higher cardiovascular fitness level is associated to better cognitive dual-task performance in master athletes: mediation by cardiac autonomic control. Brain Cogn. 2018;125:127-134. doi:10.1016/j.bandc.2018.06.003

132. de Oliveira Matos F, Vido A, Garcia WF, Lopes WA, Pereira A. A neurovisceral integrative study on cognition, heart rate variability, and fitness in the elderly. Front Aging Neurosci. 2020;12:51. doi:10.3389/fnagi.2020.00051

133. Antila K. Quantitative characterization of heart rate during exercise. Scand J Clin Lab Invest Suppl. 1979;(153):3-68. doi:10.3109/00365517909108876

134. Tsuji H, Venditti FJ, Manders ES, et al. Reduced heart rate variability and mortality risk in an elderly cohort. The Framingham Heart Study. Circulation. 1994;90(2):878-883. doi:10.1161/01.CIR.90.2.878

135. Cha S-A, Park Y-M, Yun J-S, et al. Time- and frequency-domain measures of heart rate variability predict cardiovascular outcome in patients with type 2 diabetes. Diabetes Res Clin Pract. 2018;143:159-169. doi:10.1016/j.diabres.2018.07.001

136. Yperzeele L, van Hooff R-J, Nagels G, De Smedt A, De Keyser J, Brouns R. Heart rate variability and baroreceptor sensitivity in acute stroke: a systematic review. Int $J$ Stroke. 2015;10 (6):796-800. doi:10.1111/ijs. 12573

137. Bosquet L, Gamelin F-X, Berthoin S. Is aerobic endurance a determinant of cardiac autonomic regulation? Eur J Appl Physiol. 2007;100(3):363-369. doi:10.1007/s00421-007-0438-3

138. Abhishekh HA, Nisarga $P$, Kisan R, et al. Influence of age and gender on autonomic regulation of heart. J Clin Monit Comput. 2013;27(3):259-264. doi:10.1007/s10877-012-9424-3

139. Dantas EM, Kemp AH, Andreão RV, et al. Reference values for short-term resting-state heart rate variability in healthy adults: results from the Brazilian Longitudinal Study of Adult Health-ELSA-Brasil study. Psychophysiology. 2018;55(6): e13052. doi:10.1111/psyp.13052

Vascular Health and Risk Management

\section{Publish your work in this journal}

Vascular Health and Risk Management is an international, peerreviewed journal of therapeutics and risk management, focusing on concise rapid reporting of clinical studies on the processes involved in the maintenance of vascular health; the monitoring, prevention and treatment of vascular disease and its sequelae; and the involvement
140. Huikuri HV, Ylitalo A, Pikkujämsä SM, et al. Heart rate variability in systemic hypertension. Am J Cardiol. 1996;77 (12):1073-1077. doi:10.1016/S0002-9149(96)00135-X

141. Saleh MC, Connell BJ, Saleh TM. Autonomic and cardiovascular reflex responses to central estrogen injection in ovariectomized female rats. Brain Res. 2000;879(1-2):105-114. doi:10.1016/ s0006-8993(00)02757-8

142. Dart AM, Du X-J, Kingwell BA. Gender, sex hormones and autonomic nervous control of the cardiovascular system. Cardiovasc Res. 2002;53(3):678-687. doi:10.1016/s0008-6363(01)00508-9

143. Davy KP, Desouza CA, Jones PP, Seals DR. Elevated heart rate variability in physically active young and older adult women. Clin Sci. 1998;94(6):579-584. doi:10.1042/cs0940579

144. Ribeiro TF, Azevedo GD, Crescêncio JC, et al. Heart rate variability under resting conditions in postmenopausal and young women. Braz J Med Biol Res. 2001;34(7):871-877. doi:10.1590/ s0100-879x2001000700006

145. Neves VFC, Silva de Sá MF, Gallo L, et al. Autonomic modulation of heart rate of young and postmenopausal women undergoing estrogen therapy. Braz J Med Biol Res. 2007;40 (4):491-499. doi:10.1590/s0100-879x2007000400007

146. Souza HCD, Tezini GC. Autonomic cardiovascular damage during post-menopause: the role of physical training. Aging Dis. 2013;4(6):320-328. doi:10.14336/AD.2013.0400320

147. Thawornkaiwong A, Preawnim S, Wattanapermpool J. Upregulation of $\beta 1$-adrenergic receptors in ovariectomized rat hearts. Life Sci. 2003;72(16):1813-1824. doi:10.1016/S00243205(02)02473-6

148. Kam KWL, Qi JS, Chen M, Wong TM. Estrogen reduces cardiac injury and expression of $\beta_{1}$-adrenoceptor upon ischemic insult in the rat heart. $J$ Pharmacol Exp Ther. 2004;309(1):8-15. doi:10. 1124/jpet.103.058339

149. Sherwood A, Park SB, Hughes JW, et al. Cardiovascular hemodynamics during stress in premenopausal versus postmenopausal women. Menopause. 2010;17(2):403-409. doi:10.1097/gme.0b01 3e3181b9b061

150. Tezini GC, Dias DPM, Souza HCD. Aerobic physical training has little effect on cardiovascular autonomic control in aging rats subjected to early menopause. Exp Gerontol. 2013;48 (2):147-153. doi:10.1016/j.exger.2012.11.009

151. Perciaccante A, Fiorentini A, Paris A, Serra P, Tubani L. Circadian rhythm of the autonomic nervous system in insulin resistant subjects with normoglycemia, impaired fasting glycemia, impaired glucose tolerance, type 2 diabetes mellitus. BMC Cardiovasc Disord. 2006;6(1):19. doi:10.1186/1471-2261-6-19

152. Sverrisdóttir YB, Mogren T, Kataoka J, Janson PO, Stener-Victorin E. Is polycystic ovary syndrome associated with high sympathetic nerve activity and size at birth? Am J Physiol Endocrinol Metab. 2008;294 (3):E576-581. doi:10.1152/ajpendo.00725.2007

153. Nohara K, Waraich RS, Liu S, et al. Developmental androgen excess programs sympathetic tone and adipose tissue dysfunction and predisposes to a cardiometabolic syndrome in female mice. Am J Physiol Endocrinol Metabol. 2013;304(12):E1321-E1330. doi:10.1152/ajpendo.00620.2012 of metabolic disorders, particularly diabetes. This journal is indexed on PubMed Central and MedLine. The manuscript management system is completely online and includes a very quick and fair peerreview system, which is all easy to use. Visit http://www.dovepress. $\mathrm{com} /$ testimonials.php to read real quotes from published authors. 